\title{
Factors associated with genital chlamydial and gonococcal infection in females
}

\author{
Gavin Hart
}

\begin{abstract}
Background-Predictors of chlamydia and gonorrhoea can be used to increase the cost-effectiveness and acceptability of screening programmes, and allow targeting of control strategies.

Methods-All women attending an STD clinic in 1988-1990 were offered screening for chlamydia and gonorrhoea, and the test results correlated with a wide range of potential predictors using multiple logistic regression.
\end{abstract}

Results-Of 4822 attenders, 3533 (73.3\%) were tested for chlamydia over a total of 5430 episodes, yielding 348 (6.4\%) positives, and $3510(72 \cdot 8 \%)$ were tested for gonorrhoea over a total of 5450 episodes, yielding $100(1.0 \%)$ positives. Independent predictors of chlamydial infection were being an STD contact, having endocervical gonorrhoea, being under 25 , not having genital herpes, being Aboriginal, using oral contraception, not having a steady partner and having vaginal discharge or dysuria. For gonorrhoea such predictors were being Aboriginal, an STD contact, under 25 , tattooed, having vaginal discharge or dysuria, and having had sex outside the state in the past three months. Selective screening criteria for gonorrhoea provided $91 \%$ of positives, eliminated the need for $42 \%$ of tests and resulted in an increased yield ratio of 1.5 whereas the corresponding outcomes for screening criteria for chlamydia were $91 \%, 29 \%$ and $1 \cdot 3$, respectively.

Conclusions-The diversity of STD epidemiology requires development of empirical screening guidelines for diverse settings. Standardisation of methodology to facilitate comparisons and extrapolation should include investigation of a wide range of variables, available before patient examination, by multivariate analysis, and choice of selective criteria to cover at least $90 \%$ of the infected population as well as resulting in a substantially increased yield (preferably an increased yield ratio of at least $1 \cdot 5$ ).

STD Control Branch, Box 65, Rundle Mall PO, South Australia 5000 G Har

Address for correspondence to: Dr G Hart

Accepted for publication 20 March 1992
Genital chlamydia infection is the most prevalent bacterial sexually transmitted disease (STD) ${ }^{1}$ and may lead to serious complications in men and women. Infants may also be affected at birth through vertical transmission. The most severe complications include epididymitis, ${ }^{2}$ salpingitis, infertility ${ }^{3}$ and infant pneumonia. ${ }^{4}$ The epidemiology of genital chlamydia infection is imperfectly understood, although it appears to differ from that of gonorrhoea and other STD. ${ }^{5}$ Chlamydia cases were younger and more likely to be white than gonorrhoea patients, geographic overlap of the two diseases was only about $40 \%$, with chlamydia being more diffusely distributed, and gonococcal coinfection occurred in less than $10 \%$ of chlamydia patients. ${ }^{5}$ Consequently it is not clear which groups should be targeted for health promotional activities or other control strategies. In particular, screening of sexually active women for chlamydia has been proposed as a useful public health strategy for controlling disease. ${ }^{67}$ However, in some settings it may be impractical to screen all women (for example, in general practice) and in others (such as low prevalence populations) widespread screening may not be cost effective. Appropriate guidelines for selective screening might overcome these constraints. To provide this information all women attending a major STD clinic in a 3 year period were offered screening for chlamydia and gonorrhoea, and the test results correlated with a wide range of potential predictors.

\section{Methods}

From 1988-1990 all sexually active women attending the Adelaide STD clinic (Clinic 275) were offered testing for chlamydia (using the Pharmacia enzyme immunoassay test) and gonorrhoea (by smear and culture of endocervical specimens). After cleansing the cervix of external exudate or vaginal secretions, a cotton swab was inserted $2 \mathrm{cms}$ into the external os and rotated to obtain a specimen for smear preparation and gonococcal culture. A cotton swab on a metal shaft was then inserted into the endocervical canal and rotated firmly for 5-10 seconds. The swab was then inserted into a transport tube, the metal shaft snapped and the sealed tube sent directly to the laboratory for chlamydia antigen assay. Specimens for gonococcal isolation were plated directly onto Oxoid modified New York City medium (lysed horse blood base with nutrient enrichment and antimicrobial inhibitors) and incubated at $35^{\circ} \mathrm{C}$ in an atmosphere containing $5 \%$ carbon dioxide. Colonies showing typical gonococcal morphology were confirmed as gonococci by Gram stain smear, oxidase reaction, sugar utilisation tests and coagglutination using the Phadebact monoclonal gc test kit (Karo Bio Diagnostics).
Demographic information, history, exam- ination and laboratory findings were recorded


in a standardized categorical format. ${ }^{\text {. At the }}$ conclusion of each episode of infection data were entered into an NEC Powermate computer using "dBase III plus" software. Quality control mechanisms to maximise completeness and accuracy of data included independent checking for completeness at the time of patient attendance, checking of data at the end of each episode for accurate coding and consistency, and computerized consistency checks at the time of data entry. At the end of each year computer files were subjected to consistency analysis, and aberrant casenotes were reviewed.

A variety of additional "dBase III plus" programmes were used to facilitate data analysis by recoding some fields and producing new files for specific purposes e.g. first episodes of attendance for eliciting risk factors, and files containing dichotomous variables for logistic regression. The appropriate files were then used for logistic regression using SPSS/ $\mathrm{PC}^{+}$Version 3.1 , or tabular crude or stratified analysis using "Epi Info"."

For assessment of risk factors, logistic regression analysis was confined to first episodes of attendance to avoid biases from multiple attenders. For assessment of selective screening criteria all episodes of attendance were considered and criteria, obtainable by history alone, were progressively added, in order of decreasing correlation, until at least

Table 1 Endocervical chlamydia and gonorrhoea tests and results, clinic 275, 1988-1990

\begin{tabular}{|c|c|c|c|c|c|}
\hline & \multicolumn{2}{|l|}{ Tests } & \multicolumn{2}{|c|}{ Positive } & \multirow{2}{*}{$\frac{\text { Yield }}{\%}$} \\
\hline & No. & $\%$ of all & No. & $\%$ of all & \\
\hline \multicolumn{6}{|l|}{ Chlamydia } \\
\hline $\begin{array}{l}\text { First attendance } \\
\text { All attendances }\end{array}$ & $\begin{array}{l}3533 \\
5430\end{array}$ & $\begin{array}{l}65 \cdot 1 \\
100\end{array}$ & $\begin{array}{l}283 \\
348\end{array}$ & $\begin{array}{l}81 \cdot 3 \\
100\end{array}$ & $\begin{array}{l}8 \cdot 0 \\
6 \cdot 4\end{array}$ \\
\hline \multicolumn{6}{|l|}{ Gonorrhoea } \\
\hline $\begin{array}{l}\text { First attendance } \\
\text { All attendances }\end{array}$ & $\begin{array}{l}3510 \\
5450\end{array}$ & $\begin{array}{c}64 \cdot 4 \\
100\end{array}$ & $\begin{array}{l}45 \\
53\end{array}$ & $\begin{array}{c}84 \cdot 9 \\
100\end{array}$ & $\begin{array}{l}1.3 \\
1.0\end{array}$ \\
\hline
\end{tabular}

Table 2 Risk factors for chlamydia in women (based on first clinic attendance)

\begin{tabular}{|c|c|c|c|}
\hline Factor & $\begin{array}{l}\text { Odds ratio ( } p \text { value) } \\
\text { logistic regression }\end{array}$ & $\begin{array}{l}\text { Crude odds ratio } \\
\text { (95\% confidence limits) }\end{array}$ & $\begin{array}{l}\text { \% of } \\
\text { Positives }\end{array}$ \\
\hline $\begin{array}{l}\text { STD Contact } \\
\text { Endocervical GC } \\
\text { No herpes } \dagger \\
\text { Age under } 25 \\
\text { Aboriginal } \\
\text { Oral contraception } \\
\text { No steady partnerł } \\
\text { Discharge/dysuria } \\
\text { Tattoos } \\
\text { IV drug use } \\
\text { Multiple partners } \$ \\
\text { No previous STD } \\
\text { Unmarriedt† } \\
\text { Prostitute } \\
\text { Pregnant } \\
\text { Nulligravid } \\
\text { Unemployed } \\
\text { Sex outside state } \\
\text { Warts† } \\
\text { Nulliparous }\end{array}$ & $\begin{array}{l}3 \cdot 7 \| \\
3 \cdot 3^{(0.0008)} \\
2 \cdot 9^{(0.043)} \\
2 \cdot 4 \| \\
2 \cdot 3^{\prime}(0.023) \\
1 \cdot 5(0.0045) \\
1 \cdot 4(0.0098) \\
1 \cdot 4(0.032) \\
1 \cdot 5(0.062) \\
1 \cdot 4^{\star \star} \\
1 \cdot 0^{\star \star} \\
1 \cdot 3^{\star \star} \\
1 \cdot 3^{\star \star} \\
0 \cdot 6^{\star \star} \\
1 \cdot 3^{\star \star} \\
1 \cdot 2^{\star \star} \\
0 \cdot 9^{\star \star} \\
1 \cdot 2^{\star \star} \\
1 \cdot 0^{\star \star} \\
1 \cdot 0^{\star \star}\end{array}$ & 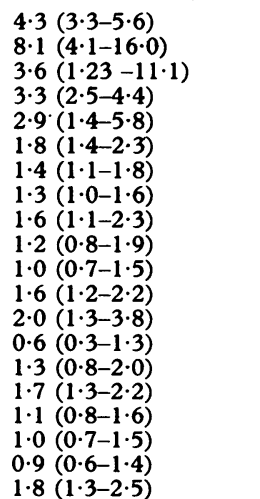 & $\begin{array}{r}45 \cdot 2 \\
5 \cdot 7 \\
98 \cdot 6 \\
76 \cdot 3 \\
3 \cdot 9 \\
55 \cdot 8 \\
53 \cdot 4 \\
30 \cdot 4 \\
15 \cdot 2 \\
10 \cdot 2 \\
19 \cdot 1 \\
79 \cdot 9 \\
92 \cdot 2 \\
3 \cdot 5 \\
9 \cdot 5 \\
68 \cdot 6 \\
20 \cdot 1 \\
11 \cdot 3 \\
10 \cdot 6 \\
83 \cdot 0\end{array}$ \\
\hline
\end{tabular}

« STD not specified

t refers to current clinical genital infection

$¥$ in the past three months

$\xi$ in the past month

$\$ \mathrm{p}$
$\| \mathrm{p}$ in 0.0001

$\|_{\star \star} \mathrm{p}<0.0001$
tin

$t$ includes never married and formerly married.
$90 \%$ of positive cases were included by the selective screening criteria. For each set of criteria, the proportion of the target population which would be tested and the overall yield in the sample were also determined.

Confidence limits for odds ratios from $2 \times 2$ tables were calculated using Cornfield's approximation, ${ }^{10}$ and Robins, Greenland and Breslow's method for stratified data. ${ }^{\text {" }}$

\section{Results}

Of 4822 females attending Clinic 275 from $1988-1990,3533(73.3 \%)$ were tested for chlamydia over a total of 5430 episodes and $3510(72 \cdot 8 \%)$ were tested for gonorrhoea over a total of 5450 episodes (table 1). Some contacts declined testing for more than one infection. The main reasons for declining a test were that there was no exposure since a previous test (for 359 (28\%) of 1289 women not tested for chlamydia), that they wished treatment only for a specific disease (of women not tested for chlamydia, $5 \%$ had herpes, $14 \%$ had warts and $6 \%$ had candidiasis), or that they perceived themselves at low risk $(52 \%$ of non-tested compared with $34 \%$ of tested women were asymptomatic, $14 \%$ of non-tested compared with $7 \%$ of tested women were over 40 , and $22 \%$ of non-tested compared with $11 \%$ of tested women had not had sex in the past 3 months). Of 331 women infected with chlamydia, $10(3.0 \%)$ had two episodes, 2 $(0.6 \%)$ had three episodes and $1(0.3 \%)$ had four episodes of infection. Independent factors (by logistic regression) associated with multiple infection were being a prostitute (odds ratio $=20 \cdot 1, p=0.016$ ), having further sex before proof of cure (odds ratio $=5.9, p=0.043$ ) and age over 24 years (odds ratio $=7 \cdot 7, p=0.015$ ). No women had more than one episode of gonorrhoea.

Being an STD contact, having endocervical gonorrhoea, being under 25 , not having genital herpes, being an Aborigine, using oral contraception, not having a steady partner and having vaginal discharge or dysuria were independently associated with chlamydia infection (table 2). Significant differences in the odds ratio obtained by logistic regression and by univariate analysis suggest confounding factors in the crude associations of chlamydia infection with having endocervical gonorrhoea, being unmarried, nulliparous or nulligravid. Age was a confounding influence in all these associations (table 3).

Being Aboriginal, an STD contact, under 25 , tattooed, having vaginal discharge or dysuria, and having had sex outside the state in the past three months were independently associated with endocervical gonorrhoea (table 4). There were no significant differences in the odds ratios obtained by logistic regression and by univariate analysis for any of the variables investigated (table 4).

The effects on the proportion of positive cases obtained, tests required to detect these cases and overall yield by applying various selective screening criteria are shown in fig 1 (for chlamydia) and fig 2 (for gonorrhoea). 
Table 3 Confounding factors in associations for chlamydia in females

\begin{tabular}{lll}
\hline Factor & Confounder(s) & Summary odds ratio" \\
\hline Cervical gonorrhoea & STD Contact by age by & $3.8(1 \cdot 9-7 \cdot 5)$ \\
oral contraception & $1 \cdot 5(1 \cdot 0-2 \cdot 4)$ \\
Unmarried & Age & $1 \cdot 1(0 \cdot 8-1 \cdot 2)$ \\
Nulligravida & Age & $1.1(0 \cdot 8-1 \cdot 5)$ \\
Nulliparous & Age & \\
\hline
\end{tabular}

Table 4 Risk factors for gonorrhoea in women (based on first clinic attendance)

\begin{tabular}{|c|c|c|c|}
\hline Factor & $\begin{array}{l}\text { Odds ratio ( } p \text { value) } \\
\text { logistic regression }\end{array}$ & $\begin{array}{l}\text { Crude odds ratio } \\
\text { ( } 95 \% \text { confidence limits) }\end{array}$ & $\begin{array}{l}\text { \% of } \\
\text { Positives }\end{array}$ \\
\hline $\begin{array}{l}\text { Aboriginal } \\
\text { STD contact* } \\
\text { Age under } 25 \\
\text { Discharge/dysuria } \\
\text { Sex outside State } \\
\text { Tattoos } \\
\text { Nullipara } \\
\text { Multiple partners } \$ \\
\text { No steady partner } \\
\text { Unmarriedtt } \\
\text { Nulligravid } \\
\text { No previous STD } \\
\text { Warts† } \\
\text { Herpes† } \\
\text { IV drug use } \\
\text { Oral contraception } \\
\text { Unemployed } \\
\text { Prostitute } \\
\text { Pregnant }\end{array}$ & $\begin{array}{l}9 \cdot 1 \| \\
5 \cdot 1 \| \\
3 \cdot 1(0 \cdot 0073) \\
2 \cdot 7(0 \cdot 0018) \\
2 \cdot 4(0 \cdot 029) \\
2 \cdot 2(0 \cdot 045) \\
0 \cdot 4(0 \cdot 060) \\
1 \cdot 6^{\star \star} \\
1 \cdot 3^{\star \star} \\
1 \cdot 8^{\star \star} \\
1 \cdot 4^{\star \star} \\
1 \cdot 3^{\star \star} \\
1 \cdot 2^{\star \star} \\
0 \cdot 5^{\star \star} \\
1 \cdot 0^{\star \star} \\
1 \cdot 0^{\star \star} \\
0 \cdot 9^{\star \star} \\
0 \cdot 9^{\star \star} \\
1 \cdot 0^{\star \star}\end{array}$ & $\begin{array}{l}12.8(4.9-32 \cdot 1) \\
5.6(2.9-10.5) \\
3.3(1.6-7.3) \\
2.5(1.3-4.8) \\
2.0(0.9-4.4) \\
3.7(1.8-7.4) \\
0.6(0.3-1 \cdot 2) \\
1.6(0.8-3.5) \\
1.4(0.8-2 \cdot 7) \\
2.2(0.7-9.2) \\
0.9(0.5-1.6) \\
1.6(0.7-3.5) \\
0.8(0.2-2.2) \\
0.5(0.02-3.3) \\
1.2(0.4-3.3) \\
1.0(0.5-1.9) \\
1.4(0.7-3.0) \\
1.2(0.3-4 \cdot 1) \\
1.9(0.7-4.7)\end{array}$ & $\begin{aligned} 15 \cdot 6 \\
55 \cdot 6 \\
77 \cdot 8 \\
46 \cdot 7 \\
20 \cdot 0 \\
28 \cdot 9 \\
64 \cdot 4 \\
28 \cdot 2 \\
55 \cdot 6 \\
93 \cdot 3 \\
53 \cdot 3 \\
80 \cdot 0 \\
8 \cdot 9 \\
2 \cdot 2 \\
11 \cdot 1 \\
42 \cdot 2 \\
24 \cdot 4 \\
6 \cdot 7 \\
13 \cdot 3\end{aligned}$ \\
\hline
\end{tabular}

* STD not specified

$\dagger$ refers to current clinical genital infection

$¥$ in the past three months

$\xi$ in the past month

II $\mathrm{p}<0.0001$

$H$ includes never married and formerly married.

\section{Discussion}

Numerous reports ${ }^{12-14}$ have focused on guidelines to obtain maximum screening yield or develop models which are highly predictive of chlamydia infection in high risk women, and one study ${ }^{15}$ suggested screening would be cost effective for prevalences exceeding $7 \%$. This approach may be useful for settings where there is limited capacity to perform a large number of tests and the main aim is to maximise cost benefit of the testing process. However, for public health programmes which aim to restrict the spread of chlamydia in the general community, detection of a high proportion of infected individuals is required as

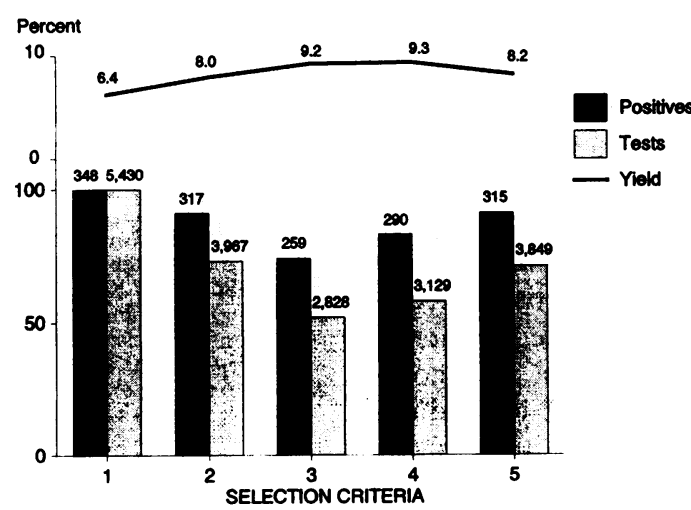

Figure 1 The proportion of positive cases detected, tests performed and overall yield (percent) for various selective screening criteria for chlamydia. Numbers of tests and positives are shown above the relevant bars. $1=$

Unselected (i.e. all women screeened), $2=$ Age under 30, $3=$ Age under $25,4=3$ or $S T D$ contact, $5=4$ or oral contraceptive use.

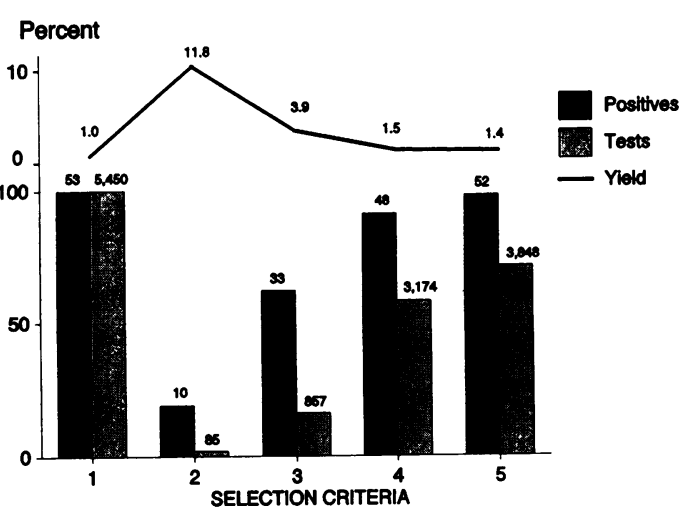

Figure 2 The proportion of positive cases detected, tests performed and overall yield (percent) for various selective screening criteria for gonorrhoea. Numbers of tests and positives are shown above the relevant bars. $1=$

Unselected, $2=$ Aborigine, $3=2$ or STD contact, $4=3$ or age under $25,5=4$ or vaginal dischargeldysuria.

those missed by the screening process continue to spread infection throughout the community. ${ }^{16}$ It is difficult to define the minimum proportion of cases to be detected because individuals differ greatly in the extent to which they continue to transmit infection and requirements may differ in different environments. Several studies ${ }^{17-19}$ have produced screening guidelines which elicit at least $90 \%$ of infections in the population tested, and this level of detection seems a reasonable target, as the spread rate from more than $10 \%$ of infected individuals could be quite substantial.

Although first episodes of attendance were used for risk factor assessment to avoid bias from multiple attenders, consideration of all attendances is necessary for defining screening criteria. The yields of both chlamydia and gonorrhoea were only marginally less when all attendances were considered, and $19 \%$ of chlamydia and $15 \%$ of gonorrhoea cases were detected after the first attendance (table 1). Correlates of infection may be detected from a patient's history (for example, age, number of sexual partners, symptoms), from examination (such as induced bleeding from the cervix, cervical ectropion) and from laboratory investigations (for example concurrent gonococcal infection). Whereas all these variables are useful in developing predictive models and guidelines for epidemiologic treatment, some cannot be used (for example laboratory investigations) and others may not be feasible indicators (such as pelvic examination findings) to help a general practitioner decide whether to advise a patient to be tested for chlamydia. In practice the clinician requires guidelines which involve information available before the patient is asked to undergo a genital examination.

As many factors are associated with infection and some may be interrelated, univariate analysis is often misleading. For instance in the present investigation, marked associations between chlamydia infection and marital status, parity, and gravidity were solely due to the confounding influence of age, and the independent association of chlamydia with endo- 
cervical gonorrhoea was greatly magnified (odds ratio $=8.1$ from univariate analysis compared with 3.3 from logistic regression) by the confounding influence of age, contraceptive use and exposure to infected partners (table 3). Consequently it is necessary to assess a wide range of potential correlates of infection by multivariate methods to minimize faulty conclusions about the primary predictors of disease.

The actual contribution of any predictor to the proportion of positives detected will be influenced by the magnitude of the association and the frequency of the predictor in the population. Thus a predictor which produces a relative risk of even 10-20 may not be useful if only $1-2 \%$ of the target population has this characteristic. In practice variables linked to less than $15 \%$ or more than $85 \%$ of the cases of infection are of limited value as selective screening criteria.

The approach in the present study was to add progressively criteria, in order of decreasing correlation, until at least $90 \%$ of positives were included by the selective screening guidelines. For each set of criteria, the proportion of the target population which would be tested was also determined. The difference in percentage of tests required and percentage of positives obtained is a reflection of the degree to which the yield will be increased compared with the yield in the unselected population (the increased yield ratio).

For gonorrhoea, testing Aborigines, STD contacts and women under 25 detects $91 \%$ of positives, eliminates the need for $42 \%$ of tests and results in an increased yield ratio of 1.5 . For chlamydia, selective criteria were less satisfactory. Testing women under 25, STD contacts and those using oral contraceptives detects $91 \%$ of positives, but eliminates only $29 \%$ of tests and results in an increased yield ratio of $1 \cdot 3$. Screening all women under the age of 30 produces a similar outcome (fig 2).

Some other studies ${ }^{17-19}$ have developed screening guidelines for detecting at least $90 \%$ of chlamydia infections with more satisfactory increased yield ratios of $1.4-1.8$, but many others have been less successful, ${ }^{20-22}$ often finding age alone as predictive as multiple variables. As the epidemiology of infection obviously varies in different locations, empirical guidelines need to be developed for diverse settings. Some factors influencing the epidemiology of infection will be the health-seeking behaviour of individuals (i.e. how readily they respond to symptoms or seek screening when asymptomatic), the degree to which clinicians screen high risk individuals, or ensure treatment of sexual contacts of infected patients, the relative contribution of casual and commercial sex (which usually implies individuals with a large number of sexual partners) to the sexual activity of a community, sexual preference and sexual practice patterns, the use of prophylaxis and recidivism patterns (that is, the numbers and characteristics of individuals with repeated infections). ${ }^{23}$ Various combina- tions of these variables result in some communities having STDs mostly in high prevalence foci (for example by ethnic, geographic or occupational groups) whereas in others the diseases are more widely spread throughout the community. Comparisons and extrapolation from studies in different environments would be facilitated by a greater standardization of methodology. Elements of this methodology could include: (1) Investigation of a wide range of variables, available before patient examination, by multivariate analysis, (2) Selective criteria should cover at least $90 \%$ of the infected population and result in a substantial increase in yield (preferably an increased yield ratio of at least $1 \cdot 5$ ).

1 Thompson SE, Washington AE. Epidemiology of sexually transmitted Chlamydia trachomatis infections. Epidemiol Rev 1983;5:96-123.

2 Holmes $\mathrm{KK}$. The chlamydia epidemic. $\mathcal{F A M A} 1981$ 245:1718-23.

3 Sweet RL Schachter J, Landers DV. Chlamydial infections in obstetrics and gynecology. Clin Obstet Gynecol 1983, 26:143-164.

4 Schachter J. Why we need a control program for the control of Chlamydia trachomatis. N Engl $f$ Med 1989, 320:802-4.

5 Zimmerman HL, Potterat JJ, Duker RL, et al. Epidemiologic differences between chlamydia and gonorrhoea. $A m$ f Public Health 1990;80:1338-42.

6 Schachter J, Stoner E, Moncada J. Screening for chlamydia infections in women attending family planning clinics. West F Med 1983;138:375-9.

7 Handsfield HH, Stamm WE, Holmes KK. Public health implications and control of sexually transmitted chlamydial infections. Sex Transm Dis 1981;8:85-86.

8 Hart G. Computerization of clinic records: The resource utilization system for a sexually transmitted disease clinic. Sex Transm Dis 1989;16:1-6.

9 Dean AG, Dean JA, Burton AH, Dicker RC. Epi Info, version 5: a word processing, database, and statistics program for epidemiology on microcomputers. USD Incorporated, Stone Mountain, Georgia, 1990.

10 Fleiss JL. Statistical Methods for Rates and Proportions. New York: John Wiley and Sons, 1981:77-75.

11 Robins J, Greenland S, Breslow NE. A general estimator for the variance of the Mantel-Haenszel odds ratio. $\mathrm{Am}$ Epidemiol 1986;124:719-23.

12 Remafedi G, Abdalian SE. Clinical predictors for Chlamydia trachomatis endocervicitis in adolescent women. $A m \mathcal{F} D i$ Child 1989;143:1437-42.

13 Addiss DG, Vaughn ML, Holzhueter MA, et al. Selective screening for Chlamydia trachomatis infection in nonurban family planning clinics in Wisconsin. Fam Planning Perceptives 1987;19:252-56.

14 Johnson BA, Poses RM, Fortner CA, Meier FA, Dalton HP. Derivation and validation of a clinical diagnostic model for chlamydial cervical infection in University women. IAMA 1990;264:3161-5.

15 Phillips RS, Aronson MD, Taylor WC, et al. Should tests for Chlamydia trachomatis cervical infection be done during routine gynecologic visits? An analysis of the costs of alternative strategies. Ann Intern Med 1987;107:188-94.

16 Hart G. Screening to control infectious diseases: evaluation of control programs for gonorrhoea and syphilis. Rev Inf Dis 1980;2(5):701-12.

17 MaCaulay ME, Riordan T, James S, et al. A prospective study of genital infections in a family planning clinic Epidemiol Infect 1990;104:55-61.

18 Phillips RS, Hanff PA, Holmes MD, et al. Chlamydia trachomatis cervical infection in women seeking routine gynecologic care: criteria for selective testing. $A m \mathcal{~} \mathrm{Med}$ 1989;86:515-20.

19 Handsfield $\mathrm{HH}$, Jasman LI Roberts PL, et al Criteria for selective screening for chlamydia trachomatis infection in women attending family planning clinics. $¥ A M A$ women attending

20 Arya OP, Mallinson H, Goddard AD. Epidemiological and clinical correlates of chlamydial infection of the cervix. $B$ clinical correlates of chlamydial

21 Magder LS, Harrison HR, Ehret JM, Anderson TS, Judson FN. Factors related to genital Chlamydia trachomatis and its diagnosis by culture in a sexually transmitted disease clinic. Am $\mathcal{F}$ Epidemiol 1988;128:298-308.

22 Winter L, Goldy AS, Baer C. Prevalence and epidemiologic correlates of Chlamydia trachomatis in rural and urban populations. Sex Transm Dis 1990;17:30-6.

23 Aral SO, Holmes KK. Epidemiology of sexual behavior and sexually transmitted diseases. In: Holmes KK, Mardh P-A, Sparling PF, Wiesner PJ (eds). Sexually Transmitted Diseases, New York, McGraw Hill, 1990:19-36.

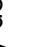

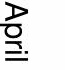

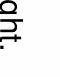

